\title{
Emerging Issues in the Diagnosis and Management of Infections Caused by Multi-Drug-Resistant, Gram-Positive Cocci
}

\author{
LENA M. NAPOLITANO
}

\begin{abstract}
Background: Rising rates of multi-drug-resistant, gram-positive cocci (e.g., methicillin-resistant Staphylococcus aureus [MRSA], vancomycin-resistant Enterococcus spp. [VRE]) have created treatment challenges for clinicians in both the hospital and community settings. These organisms have become especially problematic for hospitalized patients with pneumonia, complicated intra-abdominal infections, and skin and skin-structure infections (SSSIs).

Methods: A review of the recent literature (1990 onwards) was undertaken in order to review the epidemiology, diagnostic issues, and clinical trial data of available and forthcoming therapies for the treatment of multi-drug resistant, gram-positive isolates, with an emphasis on selected MRSA infections (i.e., pneumonia, SSSI, diabetic foot infections, blood stream) and infections caused by VRE.

Results: The rate of healthcare-associated MRSA in 2004 rose to an incidence of $59.5 \%$ in the United States compared with data from 1998-2002, making MRSA the predominant grampositive etiology of $S$. aureus infections in hospitalized patients. Methicillin-resistant $S$. aureus has also emerged as an important pathogen in both the non-ICU and community settings. Similarly, $28.5 \%$ of all enterococcal isolates were identified as vancomycin-resistant in 2003 (a 12\% increase). However, these rates may be underestimated, as detection methods for determining susceptibility have proved to be inadequate. Recognition that prior inadequate antibiotic therapy is common in patients with antibiotic-resistant bacteria, and is associated with higher mortality rates, emphasizes the importance of selecting appropriate empiric therapy. Currently available therapies for resistant gram-positive infections include quinupristindalfopristin, linezolid, and daptomycin, although each of these agents has limitations (e.g., daptomycin is not indicated for MRSA pneumonia due to inadequate lung tissue penetration and inactivation by surfactant). Three agents with broad-spectrum activity against gram-positive organisms that are at an advanced stage of testing include two new glycopeptides (oritavancin and dalbavancin), and a first-in-class glycylcycline (tigecycline). These agents have demonstrated efficacy in the treatment of SSSIs, including those caused by MRSA.

Conclusions: New antimicrobial agents are needed to combat the increasing prevalence of multi-drug-resistant, gram-positive pathogens such as MRSA. The emergence of resistance to available therapies such as vancomycin underscores this urgency.
\end{abstract}

University of Michigan School of Medicine, Ann Arbor, Michigan.

This paper was supported in part by Wyeth Pharmaceuticals. 
$\mathbf{I}_{8}$

NFECTIONS CAUSED BY multi-drug-resistant, gram-positive cocci [including methicillinresistant Staphylococcus aureus (MRSA), methicillin-resistant coagulase-negative Staphylococcus spp. (MR-CoNS), and vancomycinresistant Enterococcus spp. (VRE)] continue to increase in prevalence. At present, gram-positive pathogens are the leading cause of healthcare-associated infections (e.g., pneumonia and bacteremia) and skin and skinstructure infections, including surgical site infections. The increasing emergence of MRSA is of great concern, as MRSA strains are often multi-drug-resistant [1]. Infections due to MRSA are an important cause of morbidity and mortality in hospital patients. Moreover, increased incidences of outpatient MRSA infections have been reported recently [2]. It is well established that there is a higher mortality associated with MRSA infections compared to methicillin-susceptible $S$. aureus (MSSA) infections [3]. Resistant gram-positive pathogens are also emerging as dominant isolates in surgical patients, with MRSA now a leading cause of surgical site infection and other perioperative infections [4].

During 1996, 4,065 consecutive S. aureus strains from unique patients were collected in 21 hospital laboratories worldwide. The strains, their resistance patterns, and hospital demographic data were forwarded to Sarisa Study Group, where the strains were typed and the data were analyzed [5]. Methicillin-resistant $S$. aureus occurred at low levels in hospitals in Northern Europe $(<1 \%)$, higher levels in middle European countries, regions of the United States, New Zealand, and Australia (6-22\%), and very high levels in Southern European countries as well as in parts of the United States, Asia, and South Africa (28-63\%). Methicillin-resistant $S$. aureus strains found in large hospitals were more resistant to other antibiotics than MRSA isolates found in smaller hospitals serviced by the same laboratory. Intensive care units (ICUs) had the highest prevalence of MRSA. Strains from the lower respiratory tract showed the highest prevalence of resistance, and blood isolates the lowest. A dominant MRSA clone was found in hospitals with an MRSA frequency of more than $10 \%$. Pulsed-field gel electrophoresis typing recog- nized several of these clones as epidemic international strains of MRSA.

Current data from the National Nosocomial Infections Surveillance (NNIS) report of the U.S. Centers for Disease Control and Prevention (CDC) document that in ICU patients, $59.5 \%$ of all $S$. aureus isolates are now methicillin-resistant (Fig. 1), making MRSA the predominant pathogens of $S$. aureus infections in critical illness [6]. This represents a $12 \%$ increase in the rate of MRSA for 2004 data compared to the five prior years (1999-2003). Furthermore, MRSA has now emerged as an important pathogen in both the non-ICU and community settings (Table 1 ).

There has also been a substantial increase in VRE prevalence, with $28.5 \%$ of all enterococcal isolates identified as vancomycin-resistant, representing a $12 \%$ increase in the resistance rate for 2003, compared to the mean resistance rates of the five prior years. In contrast, rates of methicillin-resistance for coagulase-negative staphylococci (MR-CNS) remain stable, but at a high rate, with $89.1 \%$ of all isolates being methicillin-resistant.

\section{DIAGNOSIS}

The diagnosis of infections caused by multidrug-resistant gram-positive cocci requires detection of the gram-positive isolates from clinical specimens by clinical microbiology laboratories. Current methods require a number of days for growth of the pathogen in culture, subsequent isolation of pure colonies, and then identification and susceptibility testing that may require several more days to complete and report. This delay in pathogen characterization requires the use of empiric antimicrobial therapy for two to three days, and then subsequent de-escalation of antimicrobial therapy targeted at the specific pathogens identified. Because MRSA is a common pathogen in pneumonia, bacteremia, and SSSI, this strategy leads to an empiric overuse of antibiotics with MRSA activity. The rapid and accurate identification of MRSA in clinical specimens therefore has important implications for the therapy and management of both colonized and infected patients. 

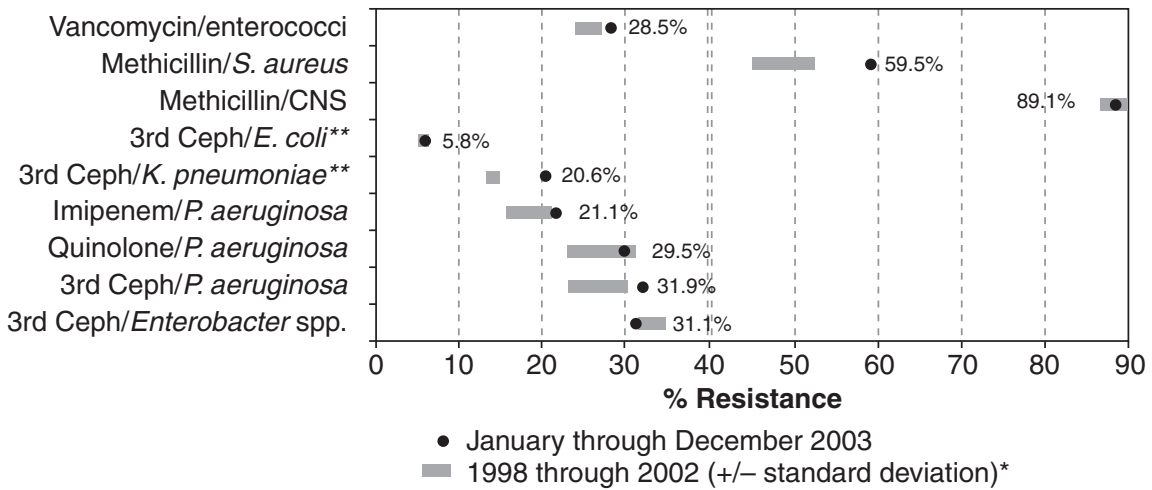

\begin{tabular}{c|c}
$\begin{array}{c}\text { Jan-Dec } \\
2003 \\
\text { No. of } \\
\text { Isolates }\end{array}$ & $\begin{array}{c}\% \\
\text { increase in } \\
\text { resistance } \\
(2003 \text { vs. } \\
\left.98-02^{*}\right)\end{array}$ \\
\hline 2048 & $12 \%$ \\
4100 & $11 \%$ \\
3336 & $1 \%$ \\
1355 & $0 \%$ \\
1068 & $47 \%$ \\
1392 & $15 \%$ \\
1825 & $9 \%$ \\
2119 & $20 \%$ \\
1411 & $-6 \%$
\end{tabular}

FIG. 1. Selected antimicrobial-resistant pathogens associated with nosocomial infections in ICU patients. Comparison of resistance rates from January through December 2003, with five years prior (1998 through 2002). From [6]. CNS, coagulase-negative staphylococci; $3^{\text {rd }}$ Ceph, resistance to third generation cephalosporins; Quinolone, resistance to either ciprofloxacin or ofloxacin. *Percent (\%) increase in resistance rate of current year (January-December 2003) compared with mean rate of resistance over previous five years (1998-2002). **Resistance for E. coli or K. pneumoniae is the rate of nonsusceptibility of these organisms to either third generation cephalosporin group or aztreonam.

Rapid detection of MRSA, directly from sterile or non-sterile clinical samples, has recently been developed and is undergoing testing. Molecular methods for the rapid identification of MRSA are generally based on the detection of a $S$. aureus-specific gene target and the mecA gene. However, such methods cannot be applied for the direct detection of MRSA from

Table 1. Pooled Means and Percentiles of the Distribution of Antimicrobial Resistance Rates by all ICUs Combined, Non-ICU InPatient Units and Outpatients, January 1998 through June 2004*

\begin{tabular}{|c|c|c|c|c|c|c|c|c|c|}
\hline \multirow[b]{2}{*}{ Location } & \multirow[b]{2}{*}{$\begin{array}{c}\text { Antimicrobial-resistant } \\
\text { pathogen }\end{array}$} & \multirow[b]{2}{*}{$\begin{array}{c}\# \\
\text { units }\end{array}$} & \multirow[b]{2}{*}{$\begin{array}{c}\# \\
\text { tested }\end{array}$} & \multirow[b]{2}{*}{$\begin{array}{l}\text { Pooled } \\
\text { mean }\end{array}$} & \multicolumn{5}{|c|}{ Percentile } \\
\hline & & & & & $10 \%$ & $25 \%$ & $50 \%$ & $75 \%$ & $90 \%$ \\
\hline All ICUs & MRSA & 157 & 22,899 & 52.90 & 20.0 & 32.7 & 48.1 & 60.3 & 67.9 \\
\hline $\begin{array}{l}\text { Non-ICU } \\
\text { Inpatient } \\
\text { Areas }\end{array}$ & MRSA & 56 & 42,502 & 46.00 & 25.6 & 31.9 & 44.9 & 52.0 & 60.8 \\
\hline Outpatient & MRSA & 49 & 35,489 & 31.10 & 15.0 & 19.3 & 24.6 & 30.8 & 49.7 \\
\hline All ICUs & $\begin{array}{l}\text { Methicillin-resistant } \\
\text { CoNS }\end{array}$ & 141 & 13,553 & 76.60 & 57.0 & 69.4 & 76.3 & 83.8 & 88.4 \\
\hline $\begin{array}{l}\text { Non-ICU } \\
\text { Inpatient } \\
\text { Areas }\end{array}$ & $\begin{array}{l}\text { Methicillin-resistant } \\
\text { CoNS }\end{array}$ & 53 & 23,525 & 65.70 & 52.2 & 57.1 & 65.2 & 71.1 & 75.9 \\
\hline Outpatient & $\begin{array}{l}\text { Methicillin-resistant } \\
\text { CoNS }\end{array}$ & 48 & 16,054 & 50.20 & 38.5 & 43.1 & 48.9 & 57.8 & 61.5 \\
\hline All ICUs & $\begin{array}{l}\text { Vancomycin-resistant } \\
\text { Enterococcus spp. }\end{array}$ & 140 & 14,140 & 13.90 & 0 & 5 & 13.6 & 24.3 & 39.2 \\
\hline $\begin{array}{l}\text { Non-ICU } \\
\text { Inpatient } \\
\text { Areas }\end{array}$ & $\begin{array}{l}\text { Vancomycin-resistant } \\
\text { Enterococcus spp. }\end{array}$ & 55 & 32,924 & 12.00 & 1.9 & 3.5 & 7.1 & 14.2 & 18.6 \\
\hline Outpatient & $\begin{array}{l}\text { Vancomycin-resistant } \\
\text { Enterococcus spp. }\end{array}$ & 46 & 24,840 & 4.60 & 0.8 & 1.3 & 3.6 & 6.1 & 9.3 \\
\hline
\end{tabular}

CoNS: Coagulase-negative staphylococci; ICU: Intensive care unit; MRSA: Methicillin-resistant staphylococcus *From [6]. 
contaminated specimens, such as nasal samples without the previous isolation, capture, or enrichment of MRSA, because these samples often contain both CoNS and S. aureus, either of which can carry mecA. One such assay uses a multiplex quantitative polymerase chain reaction (PCR), with simultaneous measurement of the following targets: 1) mecA gene, conferring methicillin resistance, common to both $S$. aureus and Staphylococcus epidermidis; 2) femA gene from S. aureus; and 3) the femA gene from $S$. epidermidis. This quantitative approach allows discrimination of the origin of the measured mecA signal. The assay uses a 96-well format that allows analysis of 30 swab samples per run and detection of the presence of MRSA with exquisite sensitivity compared to optimal culture-based techniques. The complete protocol may provide results in less than six $h$ (whereas standard procedure requires two to three days), thus allowing prompt assay results reporting [7].

Most recently, a real-time multiplex PCR assay was described that comprises five primers specific to the various SCCmec right extremity sequences, including three new sequences, in combination with a primer and three molecular beacon probes specific to the $S$. aureus chromosomal orfX gene located to the right of the SCCmec integration site [8]. This real-time PCR assay has been validated by using a variety of gram-negative and gram-positive bacterial species, as well as strains of MSSA, MRSA, methicillin-susceptible CoNS (MS-CoNS), and MR-CoNS from various countries. The assay was also used to detect MRSA directly from nasal specimens. The analytical sensitivity of the PCR assay, as evaluated with MRSA-negative nasal specimens containing a mixture of MSSA, MR-CoNS, and MS-CoNS spiked with MRSA, was approximately 25 colony-forming units (cfu) per nasal sample.

Also, a qualitative in vitro diagnostic test was described for the rapid detection of MRSA directly from clinical specimens, based upon a real-time PCR and direct detection of MRSA via amplicon hybridization with a fluorogenic, target-specific, molecular beacon probe [9]. Samples from 288 patients were analyzed for the presence of MRSA with this assay, compared to detection by either direct plating or enrichment broth-selective culture methods. This assay demonstrated $91.7 \%$ sensitivity, 93.5\% specificity, $82.5 \%$ positive predictive value, and $97.1 \%$ negative predictive value when compared to culture-based methods. The specimen processing time from start to result was approximately $1.5 \mathrm{~h}$.

The real-time PCR assays represent a rapid and powerful method that can be used for the detection of MRSA directly from clinical specimens. Assays for rapid identification of VRE are also under development. A novel susceptibility test based on a chemiluminescence assay found that PCR is reliable and rapid for detection of VRE strains in clinical laboratories, and is associated with a very short incubation time (2-4 h) [10]. These new assays will require further clinical validation.

\section{EMERGING VANCOMYCIN RESISTANCE}

Infections caused by drug-resistant pathogens are on the increase. With the initial emergence of MRSA, the glycopeptide vancomycin had been the only uniformly effective treatment for staphylococcal infections. At present, we have other antimicrobial choices for the treatment of MRSA infections. This is crucial, because both glycopeptide resistance generally and vancomycin resistance specifically continue to emerge. In 2002, the first two clinical isolates of vancomycin-resistant $S$. aureus (VRSA) containing vanA (an enterococcal resistance gene) were recovered in Michigan and Pennsylvania. Additional studies now suggest that the first two VRSA isolates were the result of independent genetic events [11]. Additional infections due to $S$. aureus with reduced susceptibility to glycopeptides (GISA) have been identified in the United States [12]. The emergence of GISA strains emphasizes the importance of the appropriate use of antibiotics, the laboratory capacity to identify resistant strains, and the importance of infection control practices [13].

Some $S$. aureus isolates have glycopeptide minimal inhibitory concentrations (MICs) in the susceptible range but have subpopulations that grow on $\geq 4 \mathrm{mg} / \mathrm{L}$ vancomycin, confirming heteroresistance. Clinical laboratory meth- 
ods for determining susceptibility have proved to be inadequate for detecting heteroresistance. A recent study documented that, among MRSA and MSSA clinical isolates, 149 (66.2\%) of 225 and $17(56.6 \%)$ of 30 isolates, respectively, grew on medium containing $2 \mathrm{mg} / \mathrm{L}$ vancomycin; 17 $(7.5 \%)$ of the MRSA and two $(6.6 \%)$ of the MSSA isolates grew on plates containing 4 $\mathrm{mg} / \mathrm{L}$ vancomycin. One isolate grew on a plate containing $6 \mathrm{mg} / \mathrm{L}$ vancomycin. This isolate escaped detection by routine susceptibility testing, but had a vancomycin MIC of $6 \mathrm{mg} / \mathrm{L}$. These observations suggest that GISA-like $S$. aureus isolates are circulating undetected, and that a continuum of decreased susceptibility exists in unselected isolates [14].

More recently, infections due to $S$. aureus with reduced vancomycin susceptibility (SARVS) have been reported increasingly [15]. The U.S. Centers for Disease Control and Prevention (CDC) S. aureus Epidemiology Study Group recently reported 19 case patients with infection due to SA-RVS; four infections were due to vancomycin-intermediate $S$. aureus (VISA; MIC $8 \mathrm{mg} / \mathrm{L}$ ) and 15 were due to nonVISA SA-RVS (MIC $\geq 4 \mathrm{mg} / \mathrm{L}$ ). Case patients both with and without VISA infection had similar clinical presentations and outcomes; the overall attributable mortality rate was $63 \%$. Isolates recovered from case patients had heterogeneous pulsed-field gel electrophoresis banding patterns, regardless of the MIC of vancomycin. This study confirmed that independent risk factors for SA-RVS infection included antecedent vancomycin use and prior oxacillinresistant $S$. aureus infection two or three months prior to the current infection [16].

\section{COMMUNITY-ACQUIRED MRSA (CA-MRSA)}

Methicillin-resistant $S$. aureus has traditionally been considered a healthcare-associated pathogen in patients with established risk factors. However, MRSA has emerged in patients who have never been hospitalized or treated with vancomycin, known as community-acquired MRSA (CA-MRSA). A prospective cohort study of 1,100 MRSA infections compared community-acquired $(131,12 \%)$ to healthcare- associated (937, 85\%) isolates [17]. Skin and soft tissue infections were more common among community-associated cases (75\%) than among health-care-associated cases $(37 \%)$ (odds ratio [OR] 4.25; 95\% confidence interval [CI], 2.97-5.90). Although CA-MRSA isolates were more likely to be susceptible to four antimicrobial classes (adjusted OR, 2.44; 95\% CI, 1.35-3.86), most community-associated infections were treated initially with antimicrobials to which the isolate was not susceptible. Community-associated isolates typically possess different exotoxin gene profiles (e.g., Panton Valentine leukocidin genes) compared with healthcare-associated isolates. This study documented that community-associated and health care-associated MRSA cases differ demographically and clinically, and their respective isolates are microbiologically distinct. This suggests that most community-associated MRSA strains did not originate in health care settings, and that their microbiological features may have contributed to their emergence in the community. Clinicians should be aware that therapy with beta-lactam antimicrobials can no longer be relied on as the sole empiric therapy for severely ill outpatients whose infections may be staphylococcal in origin.

The genomes of two disease-causing S. aureus strains isolated from distinct clinical settings have been sequenced: A recent hospitalacquired representative of an epidemic MRSA clone (MRSA252), and a representative of an invasive community-acquired MSSA clone (MSSA476) [18]. The genome sequences of both had a well conserved core region, but differed markedly in their accessory genetic elements. This study documented the crucial role that accessory elements play in the rapid evolution of $S$. aureus. The differential distribution of large mobile elements carrying virulence and drugresistance determinants may be responsible for the clinically important phenotypic differences in these strains, but additional study is required for confirmation.

Outbreaks of CA-MRSA infections, particularly skin and skin structure infections, have been described in schools, prison settings, and organized sports [19]. In many of these cases, a highly conserved CA-MRSA clone was identified that carried the gene for Panton-Valen- 
tine leukocidin and the gene complex for staphylococcal-cassette-chromosome mec type IVa resistance. Longitudinal studies have linked this dramatic increase in MRSA infections to an expanding community reservoir of MRSA genotypes with intrinsic community survival advantage [20]. In practice, however, it is difficult to delineate whether an MRSA isolate causing infection is community-acquired or healthcare-associated. Rapid real-time PCR assays to detect the Panton-Valentine leukocidin gene in $S$. aureus have been described, but are not yet in clinical use [21]. Although this information is crucial for epidemiologic studies, there is question as to whether it would be useful to the treating clinician.

Unlike healthcare-associated MRSA, CAMRSA isolates are often susceptible to several non-beta-lactam drugs, including clindamycin, trimethoprim-sulfamethoxazole, and newer tetracyclines. However, concern over the possibility of emergence of clindamycin resistance during therapy has discouraged clinicians from clindamycin use [22]. Laboratory testing (e.g., the erythromycin-clindamycin "D-zone" test) can separate strains that have the genetic potential for inducible macrolide-lincosamidestreptogramin B resistance (i.e., the presence of erm genes) during therapy from strains that are fully susceptible to clindamycin. A recent single-institution study confirmed that $56 \%$ of 161 erythromycin-resistant, clindamycin-susceptible clinical $S$. aureus isolates manifested inducible clindamycin resistance, with a significantly higher proportion $(78 \%)$ seen in pediatric isolates [23]. Despite in vitro susceptibility of CAMRSA isolates to these oral antimicrobials, little data is available regarding their clinical efficacy.

\section{MANAGEMENT}

Appropriate antimicrobial therapy is crucial for the successful treatment of infections due to antibiotic-resistant gram-positive pathogens. It has been documented that inadequate antibiotic therapy is common in patients with antibiotic-resistant bacteria such as MRSA, and is associated with higher mortality rates [24,25]. It is therefore of utmost importance to choose the correct empiric treatment for patients at risk for MRSA infection, as well as for patients who have documented MRSA infections.

Antimicrobial agents that are available currently for the treatment of MRSA infections include vancomycin, the streptogramin combination quinupristin-dalfopristin, the oxazolidinone linezolid, and the cyclic lipopeptide daptomycin (Table 2). All of these drugs are active against gram-positive bacteria, including most multi-drug-resistant strains. Linezolid has demonstrated superiority to vancomycin in clinical and microbiologic cure rates in the treatment of MRSA complicated skin and softtissue infections, and possibly pneumonia. Linezolid is available in intravenous (IV) and an oral form with $100 \%$ bioavailability, offering clinicians the option to use oral therapy at the initiation of treatment, or to switch to oral therapy from initial IV therapy. The use of the oral formulation of linezolid can reduce hospital length of stay significantly [26].

Daptomycin exerts rapid bactericidal activity in vitro, but is approved currently by the U.S. Food and Drug Administration (FDA) for the treatment of skin and soft-tissue infections only. Cyclic lipopeptides such as daptomycin have a unique mechanism of action by disruption of bacterial transmembrane electric potentials, with less likelihood for development of cross-resistance. Spontaneous acquisition of resistance in vitro is rare; hopefully this characteristic will extrapolate to the clinical setting. Rapid bactericidal activity, low potential for resistance, and a reassuring safety profile make daptomycin a useful addition to the armamentarium of antibiotics active against gram-positive pathogens [27].

Three drugs with broad-spectrum activity against gram-positive organisms are in Phase 3 clinical trials: Two new glycopeptides with potent bactericidal activity and long half-lives (oritavancin and dalbavancin), and tigecycline [28], a new, semisynthetic glycylcycline. These drugs have all shown efficacy in the treatment of SSSI. Tigecycline is a novel, first-in-class glycylcycline with expanded broad-spectrum activity against gram-positive, gram-negative, aerobic, anaerobic, and atypical bacterial species, including many resistant pathogens (i.e., VRE, MRSA, and penicillin-resistant Strep- 
tococcus pneumoniae). This new antibiotic is unique in that it demonstrates broad gram-positive and gram-negative activity. The in vitro activity of tigecycline and comparator agents was determined for 3,498 recent (2000-2003) isolates of $S$. aureus recovered from patients with either nosocomial or community-acquired infections [29]. Oxacillin-susceptible and -resistant S. aureus from both patient populations displayed identical results for tigecycline $\left(\mathrm{MIC}_{50}\right.$ and $\mathrm{MIC}_{90}$ of $0.25 \mathrm{mg} / \mathrm{L}$ and $0.5 \mathrm{mg} / \mathrm{L}$, respectively) and all strains were inhibited by $1 \mathrm{mg} / \mathrm{L}$ or less. Whereas cross resistance to other antimicrobial classes was present in oxacillin-resistant strains, susceptibility to tigecycline remained unaffected, making the compound an attractive candidate for treatment of both hospital- and community-acquired serious staphylococcal infections.

The in vitro activities of tigecycline and comparators were tested against 11,859 recent (2000 and 2002) bacterial strains recovered from patients in 29 countries with community-acquired respiratory tract disease (3,317 gram-positive and -negative strains) and skin and soft-tissue infections (8,542 gram-positive strains) [30]. All oxacillin-susceptible and -resistant $S$. aureus (5,077 strains; tigecycline $\left.\mathrm{MIC}_{90}, 0.5 \mathrm{mg} / \mathrm{L}\right)$ and coagulase-negative staphylococci $(1,432$ strains; $\left.\mathrm{MIC}_{90}, 0.5 \mathrm{mg} / \mathrm{L}\right)$, penicillin-susceptible and -resistant $S$. pneumoniae (1,585 strains; $\left.\mathrm{MIC}_{90}, \leq 0.25 \mathrm{mg} / \mathrm{L}\right)$, viridans group streptococci (212 strains; $\mathrm{MIC}_{90}, \leq 0.25-0.5 \mathrm{mg} / \mathrm{L}$ ), vancomycin-susceptible and -resistant enterococci (1,416 strains; $\left.\mathrm{MIC}_{90}, 0.25-0.5 \mathrm{mg} / \mathrm{L}\right)$, betahemolytic streptococci (405 strains; $\mathrm{MIC}_{90}$, $\leq 0.25 \mathrm{mg} / \mathrm{L})$, beta-lactamase positive and negative Haemophilus influenzae (1,220 strains; MIC $\left._{90}, 1 \mathrm{mg} / \mathrm{L}\right)$, Moraxella catarrhalis (495 strains; $\left.\mathrm{MIC}_{90}, 0.25 \mathrm{mg} / \mathrm{L}\right)$, and Neisseria meningitidis (17 strains; $\mathrm{MIC}_{90}, \leq 0.12 \mathrm{mg} / \mathrm{L}$ ) were inhibited by $2 \mathrm{mg} / \mathrm{L}$ or less of tigecycline. Whereas potency of tetracycline and doxycycline markedly decreased in various resistant organism subsets, tigecycline was unaffected, with an overall $\mathrm{MIC}_{90}$ of $0.5 \mathrm{mg} / \mathrm{L}$. These findings confirm that tigecycline maintains a truly broad spectrum of activity while enhancing potency.

TABle 2. COMPARISON OF MRSA ANTIMICROBIALS

\begin{tabular}{|c|c|c|c|c|}
\hline & Vancomycin & Quinupristin/Dalfopristin & Linezolid & Daptomycin \\
\hline FDA Indication & Multiple & $\begin{array}{l}\text { cSSSI (not MRSA), VRE } \\
\text { faecium (including } \\
\text { bacteremia) }\end{array}$ & $\begin{array}{l}\text { cSSSI, } \\
\text { Pneumonia, } \\
\text { VRE (including } \\
\text { Bacteremia) }\end{array}$ & cSSSI \\
\hline Route & IV & IV (central) & IV or PO & IV \\
\hline Dosing & $\begin{array}{l}\text { Variable, } \\
\text { depending on } \\
\text { renal function }\end{array}$ & $\begin{array}{l}\text { Q 8-12 h, altered based on } \\
\text { hepatic function }\end{array}$ & Q 12 h & Q D \\
\hline Advantage & Familiarity & Alternative to vancomycin & $\begin{array}{l}\text { Oral } \\
\text { formulation, } \\
\text { superiority to } \\
\text { vancomycin in } \\
\text { cSSSI and } \\
\text { possibly } \\
\text { pneumonia }\end{array}$ & $\begin{array}{l}\text { Potential for } \\
\text { less resistance, } \\
\text { bactericidal }\end{array}$ \\
\hline Disadvantage & $\begin{array}{l}\text { Difficulty in } \\
\text { dosing, } \\
\text { toxicity, } \\
\text { resistance } \\
\text { (VRE, GISA, } \\
\text { GRSA) }\end{array}$ & $\begin{array}{l}\text { Infusion-related } \\
\text { thrombophlebitis and } \\
\text { inflammation, myalgias, } \\
\text { arthralgias, no activity } \\
\text { against Enterococcus } \\
\text { faecalis }\end{array}$ & $\begin{array}{l}\text { Drug } \\
\text { acquisition } \\
\text { cost }\end{array}$ & $\begin{array}{l}\text { Drug } \\
\text { acquisition } \\
\text { cost, not } \\
\text { effective for } \\
\text { pneumonia }\end{array}$ \\
\hline
\end{tabular}

CSSSI: complicated skin and skin structure infections; GISA: glycopeptide-intermediate S. aureus; GRSA: glycopeptide-resistant S. aureus; IV: Intravenous; MRSA: Methicillin-resistant S. aureus; PO: Oral; QD: Daily; Qxh: Every x hours; VRE: Vancomycin-resistant enterococcus 
Tigecycline also incorporates stability to common tetracycline resistance mechanisms, making it an attractive candidate for continued clinical development against resistant pathogens.

The safety and tolerability of tigecycline administered as single or multiple doses, or at various infusion rates, were explored in three Phase 1, randomized, double-blind, placebocontrolled studies in healthy subjects [31]. Subjects in the ascending multiple-dose study received 25-to-100 $\mathrm{mg}$ doses of tigecycline as a 1 $\mathrm{h}$ infusion every $12 \mathrm{~h}$. The variable volume and infusion rate study consisted of administration of a $100 \mathrm{mg}$ loading dose of tigecycline, followed by $50 \mathrm{mg}$ every $12 \mathrm{~h}$ for five days. Serum samples were analyzed for tigecycline by validated methods, either high-pressure liquid chromatography or liquid chromatography/ tandem mass spectrometry. Systemic clearance ranged from 0.2 to $0.3 \mathrm{~L} / \mathrm{h} / \mathrm{kg}$, and the tigecycline half-life ranged from 37-67 h. Tigecycline had a large volume of distribution (7 to 10 $\mathrm{L} / \mathrm{kg}$ ), indicating extensive distribution into tissues. Tigecycline exhibited linear pharmacokinetics and was safe and well tolerated in the dose ranges examined in this study.

The promising data that have emerged recently indicate that six drugs to treat resistant S. aureus infections may be available within the next few years. As clinicians, it must be our goal to determine the appropriate indications and cost-effectiveness of each of these drugs in our treatment strategies against $S$. aureus and other gram-positive pathogens. Data regarding clinical efficacy with the use of these antibiotics in the treatment of specific disease states, including pneumonia, SSSI, and bacteremia will be reviewed to assist in this decision making.

\section{PNEUMONIA CAUSED BY METHICILLIN-RESISTANT S. AUREUS}

Over the past 15 years, the incidence of hospital-acquired pneumonia due to gram-positive organisms has increased relative to gramnegative organisms [32]. Staphylococcus aureus and Pseudomonas aeruginosa are the two most common causative pathogens in the ICU, and ventilator-associated pneumonia is the most common nosocomial infection in the ICU. The most recent CDC report of the NNIS group documented that $59.5 \%$ of all S. aureus isolates are methicillin-resistant currently, making MRSA the most common gram-positive isolate in healthcare- and ventilator-associated pneumonia. Mortality rates for MRSA pneumonia are high, ranging from 35 to $50 \%$. In a prospective analysis of all ventilator-associated pneumonia caused by $S$. aureus for a 30-month period, Rello et al. documented that mortality related directly to pneumonia was significantly higher among patients with MRSA infection (RR 20.72; 95\% CI 2.78-154.35), and previous antibiotic therapy was the most important risk factor for developing infection with MRSA [33].

Current options for antimicrobial treatment of MRSA pneumonia include vancomycin and linezolid. Quinupristin-dalfopristin is not approved by the U.S. FDA for the treatment of pneumonia because the response rate to quinupristin-dalfopristin was lower than that to vancomycin in the treatment of documented MRSA hospital-acquired pneumonia (clinical cure rates $30.9 \%$ for quinupristin-dalfopristin vs. $44.4 \%$ for vancomycin) in a prospective randomized study [34], although the results are a subset analysis of a larger trial.

The first multi-national, randomized, doubleblind, controlled trial comparing linezolid and vancomycin in the treatment of nosocomial pneumonia documented equivalent clinical cure $(66.4 \%$ vs. $68.1 \%)$ and microbiologic success $(67.9 \%$ vs. $71.8 \%)$ rates [35]. A recent retrospective analysis of data from the two prospective, randomized, double-blind registration trials of patients with gram-positive, nosocomial pneumonia documented that initial therapy with linezolid was associated with better survival and clinical cure rates than vancomycin in the MRSA cohort [36]. This study utilized a logistic regression analysis to determine the effect of treatment and other baseline variables on outcome. Logistic regression analysis confirmed that the survival difference favoring linezolid remained significant after adjusting for baseline variables (OR 2.2, 95\% CI $1.0-4.8, \mathrm{p}=0.05)$. Furthermore, Kaplan-Meier survival rates for linezolid vs. vancomycin were $80.0 \%$ vs. $63.5 \%$ for the MRSA subset $(p=0.03)$ of patients with nosocomial pneumonia. There are major limitations to this study 
in that it was a post-hoc subgroup analysis, the dosing of vancomycin (1g IV q $12 \mathrm{~h}$ ) in the control group may have been inadequate, and recent data have documented that clinical failure rates are higher in patients with MRSA isolates for which vancomycin MICs are in the 1-2 $\mu \mathrm{g} / \mathrm{mL}$ range. Finally, the use of quantitative sputum cultures was not required for the diagnosis of pneumonia, but more than $50 \%$ of patients in the $S$. aureus and MRSA subgroups had diagnoses made by invasive methods or blood culture. A further post-hoc analysis in patients with ventilator-associated pneumonia (VAP, $\mathrm{n}=544$ ) documented that linezolid was an independent predictor of clinical cure (OR 1.8 for all patients, 2.4 for gram-positive VAP, 20.0 for MRSA VAP) and survival (OR 1.6 for all patients, 2.6 for gram-positive VAP, 4.6 for MRSA VAP) [37]. Based on these re-analyzed data, some have recommended the use of linezolid as first-line treatment for patients with MRSA pneumonia. A prospective, randomized trial projected to enroll 1,200 patients with healthcare-associated pneumonia is underway to attempt to validate the findings of the posthoc analysis of the first two trials.

Putative improved outcome with linezolid may be related to the superior intrapulmonary pharmacokinetics of linezolid compared with vancomycin. A study of healthy volunteers who received oral linezolid (600 mg every $12 \mathrm{~h}$ for five doses) documented that linezolid concentrations (mean $\pm \mathrm{SD}$ ) in the fluid lining the epithelial surface of the lower respiratory tract (epithelial lining fluid [ELF]), recovered by bronchoalveolar lavage, were significantly higher than plasma concentrations at the 4-h time point (ELF $64.3 \pm 33.1$ vs. plasma $7.3 \pm 4.9$ $\mathrm{mcg} / \mathrm{mL}$ ) and also at the 12-h time point (ELF $24.3 \pm 13.3$ vs. plasma $7.6 \pm 1.7 \mathrm{mcg} / \mathrm{mL}$ ) [38]. For an MIC of 4 , the 12-h plasma area under the curve (AUC):MIC and maximum concentration:MIC were 34.6 and 3.9, respectively, and the percentage of time the linezolid concentration remained above the MIC for the 12-h dosing interval was $100 \%$; the corresponding ratios in ELF were 120 and 16.1, respectively, and the percentage of time the linezolid concentration remained above the MIC was also $100 \%$. The long plasma and intrapulmonary half-lives of linezolid and the high drug con- centrations observed provide a pharmacokinetic rationale for the use of linezolid in the treatment of pulmonary infections.

Similar findings were documented in a study of 10 adult patients who underwent diagnostic bronchoscopy and who were administered oral linezolid (600 mg q $12 \mathrm{~h}$ for 6 doses) [39]. Mean concentrations of linezolid were $13.4 \mathrm{mg} / \mathrm{L}$ in serum and $25.1 \mathrm{mg} / \mathrm{L}$ in ELF, achieving a mean site:serum concentration of 8.35 for ELF. It is known that vancomycin penetration into ELF is significantly lower than plasma. A study of 14 critically ill, ventilated patients who received vancomycin for at least five days documented that ELF vancomycin concentrations ranged from 0.4 to $8.1 \mathrm{mcg} / \mathrm{mL}$ (mean, 4.5 $\mathrm{mcg} / \mathrm{mL}$ ), versus a simultaneous mean plasma concentration of $24 \mathrm{mcg} / \mathrm{mL}$ (range, 9-37 $\mathrm{mcg} / \mathrm{mL}$ ) [40]. There was a significant relationship $(r=0.64, p<0.02)$ between vancomycin concentrations in plasma and ELF, documenting that the blood:ELF drug penetration was 6:1 (Fig. 2). Using the albumin concentration in ELF as a marker of lung inflammation, it was identified that vancomycin penetration was higher in patients with ELF albumin concentrations of $\geq 3.4 \mathrm{mg} / \mathrm{mL}$ than in patients with lower albumin concentrations $(<3.4 \mathrm{mg} / \mathrm{mL}, \mathrm{p}<0.02)$. These results suggest that vancomycin distribution into lower respiratory tract ELF is dependent upon the concentration in blood, but the ELF concentrations were well below the minimum inhibitory concentrations (MIC) for staphylococci and enterococci in patients with plasma vancomycin concentrations $<20 \mu \mathrm{g} / \mathrm{mL}$, levels that are not commonly achieved in clinical practice.

Vancomycin penetration in ELF was also studied in ten mechanically ventilated patients with MRSA pneumonia $24 \mathrm{~h}$ after the onset of treatment [41]. Vancomycin was given intravenously at a dose of $30 \mathrm{mg} / \mathrm{kg} /$ day. Vancomycin concentrations were detectable in only four of the 10 patients (range, $1-2.77 \mathrm{mcg} / \mathrm{mL}$ ), which is below the MIC for most gram-positive organisms. Concordance between high plasma concentrations $(>20 \mathrm{mcg} / \mathrm{mL})$ of vancomycin and detectable vancomycin concentrations in ELF was again noted.

Linezolid also has an advantage over vancomycin in that no requirement for dosage ad- 


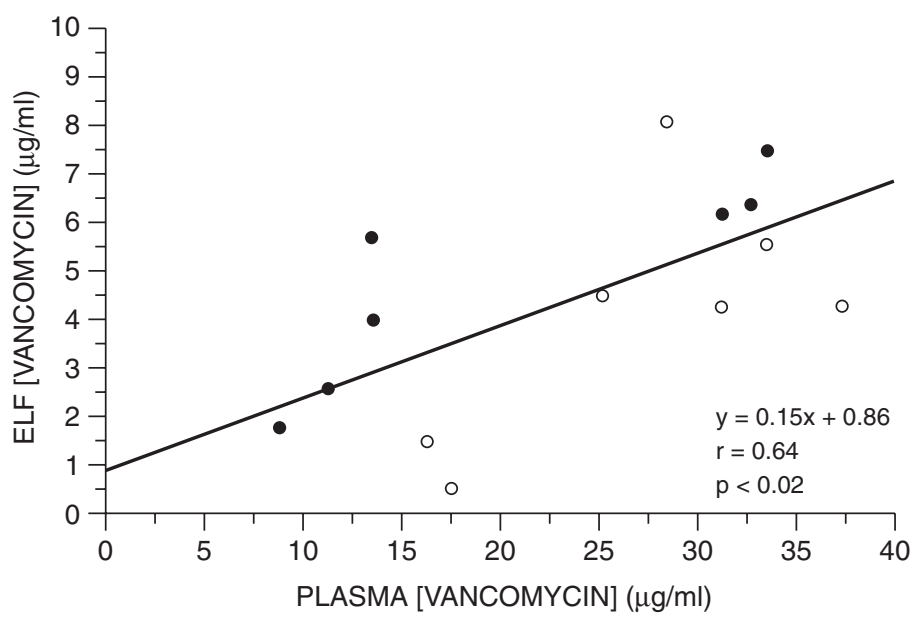

FIG. 2. Vancomycin concentrations in the plasma and epithelial lining fluid (ELF) of the lower respiratory tract. The mean vancomycin concentration in ELF $(4.5 \pm 2.3 \mathrm{mcg} / \mathrm{mL})$ represented $18 \%$ of the simultaneous concentration in plasma $(24 \pm 10 \mathrm{mcg} / \mathrm{mL})$. All patients had been receiving vancomycin for at least five days (mean duration of treatment before BAL, $6.6+1.75$ days; range, five to 11 days). Concentrations in ELF exceeded minimal inhibitory concentrations (MICs) for most gram-positive cocci when concentrations in blood were greater than $20 \mathrm{mcg} / \mathrm{mL}$. $\bigcirc$, patients with albumin level in ELF of $<3.4 \mathrm{mg} / \mathrm{mL} ; 0$, patients with albumin levels in ELF of $\geq 3.4 \mathrm{mg} / \mathrm{mL}$. From: Lamer C, de Beco V, Soler P, et al. Analysis of vancomycin entry into pulmonary lining fluid by bronchoalveolar lavage in critically ill patients. Antimicrob Agents Chemother 1993;37:281-286.

justment is necessary for patients with renal or hepatic dysfunction. Dosing of vancomycin is problematic, especially in critically ill patients with renal dysfunction or changing renal function in, and often results in under-dosing. Linezolid is associated with reversible thrombocytopenia; complete blood counts should be obtained weekly after the first week of therapy. However, the post-hoc analysis of the two randomized, double-blind studies of patients with gram-positive nosocomial pneumonia showed no difference in the incidence of new-onset thrombocytopenia (linezolid $6.4 \%$, vancomycin $7.7 \%)[42]$.

Although daptomycin is approved for the treatment of SSSI and has rapid bactericidal activity against MRSA, it should not be used for the treatment of pneumonia. Daptomycin does not achieve adequate intrapulmonary tissue concentrations, and there is evidence that the drug is inactivated by pulmonary surfactant [42a].

\section{SKIN AND SOFT-TISSUE INFECTION CAUSED BY METHICILLIN-RESISTANT S. AUREUS}

Multi-drug-resistant pathogens, including MRSA, are an increasingly common cause of complicated SSSI (cSSSI), including surgical site infections [43]. It is particularly important to recognize that MRSA has become the leading pathogen of surgical site infection in cardiovascular surgery and orthopedic surgical patients in many institutions. Current options for the treatment of cSSSI caused by MRSA include vancomycin, quinupristin-dalfopristin, linezolid, and daptomycin [44]. The characteristics, dosing, advantages and disadvantages of each of these agents for the treatment of cSSSIs are seen in Table 2.

Two randomized, open-label clinical trials in cSSSI $(n=893)$ confirmed similar clinical success rates (cure plus improvement) for quinupristin-dalfopristin, vs. oxacillin or cefazolin as comparators $(68.2 \%$ quinupristin-dalfopristin, 70.7\% comparator; 95\% CI, -10.1, 5.1 for non-inferiority) [45]. Staphylococcus aureus was the most frequently isolated pathogen in both treatment groups, but only 15 patients with documented MRSA were included in this trial. A higher rate of drug-related adverse events (AEs) related to the infusion site was reported for quinupristin-dalfopristin $(66.2 \%)$ than for the comparator regimens $(28.4 \%)$, including infusion-site inflammation, pain, and edema; other infusion-site reactions; and thrombophlebitis. Arthralgia and myalgia oc- 
curred in $2.5 \%$ to $4.6 \%$ of patients, and were the most frequently reported systemic AEs.

A preliminary study comparing linezolid and vancomycin documented equivalent clinical and microbiologic cure rates in patients with cSSSIs caused by MRSA, but had a small sample size $(n=64)$ [46]. An adequately powered open-label, multicenter, multi-national trial of 1,200 hospitalized patients with cSSSIs randomized patients to receive linezolid (IV or oral, $600 \mathrm{mg} \mathrm{q} 12 \mathrm{~h}$ ) or vancomycin (1 g IV q $12 \mathrm{~h}$ ) [47]. Clinical cure rates were equivalent in the intent-to-treat cohort $(92 \%$ vs. $89 \%)$, which included patients with cellulitis, major skin abscess, and infected surgical incisions. Linezolid was superior to vancomycin in the treatment of MRSA cSSSIs, with clinical cure rates of $94 \%$ vs. $84 \%(\mathrm{p}=0.011)$ and microbiologic efficacy rates of $89 \%$ vs. $67 \%$ ( $p<.0001$ ). Linezolid was also associated with a significant reduction in IV drug administration (1.8 vs. 12.6 days, $p<0.0001)$ and decreased hospital mean length of stay (8.1 vs. 10.7 days, $\mathrm{p}<0.01$ ); $52 \%(\mathrm{n}=308)$ of the linezolid-treated patients received only oral linezolid therapy. Post-hoc analysis of the cohort with surgical site infection $(\mathrm{n}=135)$ documented that clinical success at test-of-cure was similar in patients treated with linezolid or vancomycin [48]. However, in those patients with MRSA isolated, linezolid yielded a significantly higher microbiologic cure rate $(87 \%$ vs. $48 \%$, respectively; $95 \%$ CI 16.51-60.27; $\mathrm{p}<0.01)$ compared to those who received vancomycin.

A recent study examined the pharmacokinetics and antibacterial activity of oral linezolid against selective skin/soft-tissue pathogens in obese patients $(>50 \%$ over their calculated ideal body weight) [49]. Serum concentrations of oral linezolid in the obese patients were diminished compared with those of healthy volunteers, but still provided prolonged serum inhibitory activity against common pathogens associated with cSSSIs. Bactericidal activity was also observed against selective pathogens. Caution is advised if treating an obese patient with oral linezolid for infection with a less susceptible strain (MIC $\geq 4.0 \mathrm{mg} / \mathrm{L}$ ) of $S$. aureus.

Daptomycin is approved by the U.S. FDA for the treatment of cSSSI, and has excellent bactericidal activity in vitro against MRSA [50] and other gram-positive pathogens, including MR-CoNS, vancomycin-resistant $S$. aureus, penicillin-resistant S. pneumoniae, and VRE [51]. As a parenteral agent that is administered once daily, it offers a convenient regimen for therapy that is continued after discharge, with a favorable side effect profile. The safety and efficacy of daptomycin for treatment of cSSSI are comparable to conventional therapy. In two randomized, investigator-blinded, multicenter international trials in 1,092 patients with cSSSIs, daptomycin $4 \mathrm{mg} / \mathrm{kg}$ / day IV was as effective as standard therapy (either a semi-synthetic penicillin 4-12 g/day IV or vancomycin $1 \mathrm{~g}$ IV q 12 h) [52]. Among 902 clinically evaluable patients, clinical success rates were $83.4 \%$ and $84.2 \%$ for the daptomycin- and comparator-treated groups, respectively (95\% CI for non-inferiority, -4.0 to 5.6). In patients with cSSSIs, the AE profiles of daptomycin and vancomycin were similar. Creatine phosphokinase (CPK) concentrations increased in $2.8 \%$ of daptomycin recipients and $1.8 \%$ of patients who received standard therapy; only one daptomycin recipient experienced increased CPK concentrations and muscle symptoms that were attributed to therapy.

Several investigational agents, such as dalbavancin, oritavancin, and tigecycline, are in Phase 3 clinical trials and are likely to become available for clinical use in the near future. With their long half-lives, these newer antimicrobial agents have an advantage of less frequent dosing, and possibly a lower likelihood for development of resistance [53]. They have proven activity against highly-resistant organisms, and when available, should ideally be used only when resistant pathogens are documented or suspected.

Dalbavancin, a novel glycopeptide with a long elimination half-life ( $\sim 9-12$ days), was compared to standard antimicrobial therapy for cSSSIs in a randomized, controlled, openlabel, phase 2, proof-of-concept trial. Adults received either $1.1 \mathrm{~g}$ of dalbavancin as a single IV infusion, $1.0 \mathrm{~g}$ of dalbavancin IV and then 0.5 g IV one week later, or a prospectively defined standard-of-care regimen [54]. A gram-positive pathogen was isolated from samples obtained from $41(66 \%)$ of 62 patients at baseline; S. aureus was the most prevalent species $(83 \%$ of 
pathogens). Clinical success rates were $94.1 \%$ among patients treated with two doses of dalbavancin, $61.5 \%$ among patients treated with one dose of dalbavancin, and $76.2 \%$ among patients treated with a standard regimen. Drug-related AEs were similar among the three groups. These findings suggest that a regimen of two doses of dalbavancin administered one week apart is effective in the treatment of complicated, gram-positive, bacterial CSSSIs, and warrants further study.

Dalbavancin was recently tested in vitro against 146 staphylococci, and found to be more potent than other drugs tested, with a $\mathrm{MIC}_{90}$ of $0.06 \mathrm{mg} / \mathrm{L}$ by microdilution. For all strains, MICs of vancomycin, linezolid, ranbezolid, oritavancin, daptomycin, and quinupristin-dalfopristin were all $\leq 4.0 \mathrm{mg} / \mathrm{L}$. Dalbavancin was bactericidal at four times the MIC against all six strains tested [55].

Oritavancin, a semisynthetic glycopeptide with bactericidal activity in vitro against grampositive pathogens, is also undergoing investigation for the treatment of patients with cSSSIs. In a phase 3, double-blind, randomized trial, 1,267 patients with cSSSI caused by grampositive pathogens were randomized 2:1 to receive oritavancin ( $200 \mathrm{mg} /$ day IV for three to seven days, followed by oral placebo) or vancomycin plus cephalexin (15 mg/kg vancomycin q $12 \mathrm{~h}$ IV for three to seven days, followed by $1 \mathrm{~g}$ oral cephalexin twice daily) (total therapy 10-14 days). Of the 187 patients with diabetes mellitus in the clinically evaluable patient population, $62 \%$ and $57 \%$ of the oritavancin and vancomycin patients were cured, respectively [56]. Efficacy in the oritavancin patients was achieved with approximately onehalf the number of days of active antimicrobial therapy. Furthermore, fewer oritavancin patients $(55 \%)$ experienced AEs compared to the vancomycin patients (69\%).

Tigecycline, a broad-spectrum glycylcycline antibiotic, is also being investigated for the treatment of serious infections in hospitalized patients, including cSSSIs. Two phase 3, randomized, double-blind studies were conducted in hospitalized patients with cSSSIs to determine tigecycline safety and efficacy compared with vancomycin plus aztreonam $(\mathrm{V}+\mathrm{A})$. One study was conducted in the Americas whereas the second study was conducted worldwide. Patient numbers were similar in both studies, with 537 and 520 patients, respectively, in the clinically modified, intent to-treat (c-mITT) population; 397 and 436 patients, respectively, in the clinically evaluable (CE) population; and 228 and 312 patients, respectively, in the microbiologically evaluable (ME) population. Clinical cure rates in the c-mITT and CE populations at test-of-cure were similar in both studies: for the U.S. study (tygecycline vs. V\&A c-mITT $76 \%$ vs. $83 \%$; CE $84 \%$ vs. $90 \%$ ); for the worldwide study (tygecycline vs. V\&A c-mITT $77 \%$ vs. $82 \%$; CE $87 \%$ vs. $94 \%$. In both studies, the overall frequency of adverse events (AEs) was similar between groups. Patients treated with tigecycline had more nausea and vomiting; however, rash and increases in alanine transaminase (ALT) and aspartate transaminase (AST) concentrations were more frequent in the $\mathrm{V}+\mathrm{A}$ group, resulting in more frequent discontinuation of therapy [57].

\section{FOOT INFECTIONS OF PATIENTS WITH DIABETES MELLITUS (DIABETIC FOOT INFECTIONS)}

The causative pathogens in diabetic foot infections are gram-positive cocci, with an increasing percentage of multi-drug-resistant pathogens, including MRSA. A recent large study of 371 patients with diabetic foot infection documented equivalent efficacy of linezolid and ampicillin/sulbactam for clinical cure in the intent-to-treat cohort, but linezolid clinical outcomes were superior for patients with infected ulcers $(81 \%$ vs. $68 \%$, p < 0.05) [58].

An analysis of a subset of diabetic patients with infected ulcers enrolled in two randomized, controlled, investigator-blind trials of patients with cSSSIs (caused presumptively by gram-positive organisms) compared daptomycin against semi-synthetic penicillins or vancomycin [59]. Among 133 patients with a diabetic ulcer infection, 103 were clinically evaluable; 47 received daptomycin and 56 received a comparator. Most infections were monomicrobial, and $S$. aureus was the predominant pathogen. Success rates for patients treated with daptomycin or the comparators 
were not different for clinical (66\% vs. $70 \%, 95 \%$ CI for non-inferiority, $-14.4,21.8$ ) or microbiological outcomes (overall or by pathogen).

\section{METHICILLIN-RESISTANT STAPHYLOCOCCUS AUREUS BLOOD STREAM INFECTION}

Blood stream infection (bacteremia) is a common cause of nosocomial infection in adult ICUs, comprising $19 \%$ of all such infections. Gram-positive organisms are causative in $64 \%$ of nosocomial bacteremias; the three most common organisms are CoNS, S. aureus, and enterococci [60]. Data from the NNIS group documented that $59.5 \%$ of all $S$. aureus isolates in the U.S. are MRSA. Two recent meta-analyses have documented that MRSA bacteremia is associated with a significantly higher mortality rate than MSSA bacteremia [61,62]. Delayed effective antimicrobial therapy for $S$. aureus bacteremia was associated with increased infection-related mortality by multivariate analysis (OR, 3.8; 95\% CI, 1.3-11.0; $\mathrm{p}=0.01$ ), and was associated with a longer hospital stay (20.2 days vs. 14.3 days; $p=0.05$ ). Furthermore, delayed treatment of MRSA bacteremia was associated with an even higher risk of death (OR, 8.3; 95\% CI, 2.6-16.8) [63]. Prompt initiation of appropriate antibiotic therapy is therefore mandatory in the treatment of MRSA bacteremia. Current options for the treatment of MRSA bacteremia include vancomycin and linezolid. There are no prospective randomized comparative studies of these agents in the treatment of MRSA bacteremia.

There is also concern that heavy vancomycin use has led to the increased incidence of $S$. aureus isolates with reduced susceptibility to vancomycin [64]. A recent study [65] assessed all 53 episodes of MRSA bacteremia at a single hospital during a 12-month period, and compared those due to heterogeneous vancomycinintermediate $S$. aureus (hVISA; $\mathrm{n}=5,9.4 \%$ ) with those due to vancomycin-susceptible MRSA $(n=48)$. Patients with hVISA bacteremia were more likely to have infections with a high bacterial load $(p=0.001)$, vancomycin treatment failure (persistent fever and bacteremia for $>7$ days after the start of ther- apy; $\mathrm{p}<0.001)$, and initially low serum vancomycin concentrations $(\mathrm{p}=0.006)$. These clinical markers of hVISA bacteremia may help focus diagnostic efforts and treatment.

Recent evidence also suggests that vancomycin's clinical efficacy is linked with the microbiological properties of the MRSA clinical isolates, specifically the vancomycin MIC [66]. Vancomycin susceptibility testing was performed, and bactericidal activity was determined for isolates from 30 different patients with MRSA bacteremia for whom clinical and microbiological outcome data were available. The majority of these patients had been enrolled previously in multicenter prospective studies of MRSA bacteremia refractory to conventional vancomycin therapy. For MRSA isolates with vancomycin MICs $\leq 0.5 \mathrm{mcg} / \mathrm{mL}$, vancomycin was $55.6 \%$ successful in the treatment of bacteremia, whereas vancomycin was only $9.5 \%$ effective in cases in which vancomycin MICs for MRSA were 1-2 mcg/mL. Therefore, a substantial risk for vancomycin treatment failure in MRSA bacteremia begins to emerge even when increasing vancomycin MICs are still well within the susceptible range. This study also demonstrated that vancomycinsusceptible clinical MRSA isolates may manifest considerable heterogeneity in vitro with respect to vancomycin MIC and the effectiveness of bacterial killing by vancomycin. These differences appear to affect the clinical efficacy of vancomycin and the probability of successful treatment of MRSA bacteremia.

New antimicrobial agents for the treatment of MRSA bacteremia are therefore necessary. A prospective, randomized trial of linezolid vs. vancomycin for the treatment of CR-BSI is currently underway. Daptomycin is also currently undergoing clinical investigation for the treatment of gram-positive bacteremia. Recently, a phase 2, open-label, randomized, controlled, multicenter study of 75 adult patients with catheter-related blood stream infections (CRBSIs) compared treatment with IV dalbavancin, administered as a single 1000-mg dose, followed by a 500-mg dose one week later, with IV vancomycin administered twice daily for 14 days [67]. Gram-positive bacteria isolated in this study included coagulase-negative staphylococci and S. aureus, including MRSA. Infected 
patients who received weekly dalbavancin $(\mathrm{n}=33)$ had an overall success rate $(87.0 \% ; 95 \%$ CI, $73.2 \%-100.0 \%$ ) that was significantly higher than that of those who received vancomycin $(\mathrm{n}=34)(50.0 \%$; 95\% CI, 31.5\%-68.5\%). Adverse events and laboratory abnormalities were comparable for the two drugs and generally mild.

\section{VANCOMYCIN-RESISTANT ENTEROCOCCUS}

Vancomycin-resistant enterococcal infections are increasing in incidence in solid organ transplant recipients and have a high associated mortality rate (up to $83 \%$ ). Treatment options for VRE infections include quinupristin/ dalfopristin and linezolid on the basis of in vitro susceptibility and clinical efficacy from multicenter clinical trials [68]. Quinupristin/dalfopristin has bacteriostatic activity against vancomycin-resistant E. faecium ( $\mathrm{MIC}_{90}=2 \mathrm{mg} / \mathrm{L}$ ) but is not active against Enterococcus faecalis $\left(\mathrm{MIC}_{90}=16 \mathrm{mg} / \mathrm{L}\right)$. In a non-comparative, openlabel, emergency-use program in 396 patients who were infected with gram-positive isolates resistant or refractory to conventional therapy, or who were intolerant of conventional therapy, quinupristin/dalfopristin was administered at $7.5 \mathrm{mg} / \mathrm{kg}$ every $8 \mathrm{~h}$ [69]. The clinical response rate in the microbiologically-evaluable subset was $70.5 \%$, and a $65.8 \%$ overall response (favorable clinical and bacteriological outcome) was observed. Resistance to quinupristin/dalfopristin on therapy was observed in $6 / 338(1.8 \%)$ of VRE strains. The most common systemic adverse events related to treatment were arthralgias $(9.1 \%)$ and myalgias $(6.6 \%)$.

Linezolid has bacteriostatic activity against both vancomycin-resistant $E$. faecium $\left(\mathrm{MIC}_{90}=\right.$ 2 to $4 \mathrm{mg} / \mathrm{L}$ ) and E. faecalis (MIC $90=2$ to 4 $\mathrm{mg} / \mathrm{L})$ [68]. This agent was studied in a similar emergency-use protocol for multi-resistant, gram-positive infections, with 55 of 133 evaluable patients infected with VRE [68]. Cure rates for the most common sites were complicated skin and soft tissue, $87.5 \%$; primary bacteria, 90.9\%; peritonitis, 91.7\%; other abdominal/ pelvic infections, 91.7\%; and CR-BSI, 100\%. In a separate blinded, randomized, multicenter trial for VRE infection at a variety of sites, lowdose linezolid (200 mg IV every $12 \mathrm{~h}$ ) was compared to high-dose therapy (600 mg IV every $12 \mathrm{~h}$ ) with optional conversion to oral administration [68]. A non-significant dose response was seen, with a $67 \%(39 / 58)$ and 52\% (24/46) cure rate in the high- and low-dose groups, respectively.

A recent report documented experience with linezolid in an open-label, compassionate-use trial at 53 U.S. centers for the treatment of documented VRE infections in 85 patients with solid organ transplants [70]. Blood cultures were positive for VRE in 43 patients, whereas 42 patients had other sites of infection. Fiftythree percent of patients responded well to treatment, with clinical resolution of the infection (62.4\% survival rate). The mean duration of therapy for cured patients was 23.5 days. Thirty-two patients died (37.6\% mortality rate), 28 due to sepsis and organ failure $(32.9 \%$ failure rate), and four due to unrelated causes. Adverse reactions to linezolid included thrombocytopenia $(4.7 \%)$, decreased leukocyte count $(3.5 \%)$, and an increase in blood pressure $(1.2 \%)$, none of which led to discontinuation of therapy.

Quinupristin/dalfopristin $(7.5 \mathrm{mg} / \mathrm{kg}$ every $8 \mathrm{~h}$ ) and linezolid (600 mg every $12 \mathrm{~h}$ ) were compared recently in terms of safety and efficacy in the treatment of VRE infections in a prospective randomized study of 40 cancer patients [71]. Linezolid and quinupristin/dalfopristin had comparable clinical responses (58\% and $43 \%$, respectively, $\mathrm{p}=0.6$ ). Myalgias or arthralgias occurred at a frequency of $33 \%$ in patients who received quinupristin/dalfopristin, but were not observed in the linezolid group $(p=0.03)$. In contrast, drug-related thrombocytopenia occurred in $11 \%$ of patients who received linezolid, but was not observed in the quinupristin/dalfopristin group $(\mathrm{p}=$ 0.2 ). In cancer patients, quinupristin/dalfopristin treatment is associated with a relatively high frequency of myalgias/arthralgias; however, profound thrombocytopenia might limit the choice of linezolid in a subpopulation of cancer patients.

Linezolid resistance has been reported in a small number of strains of E. faecium, which appears to be secondary to a base-pair mutation 
in the genome encoding for the bacterial 23S ribosomal binding site [68]. These cases have several features in common, including prolonged duration of antimicrobial therapy, inadequate source control, or non-removal of infected devices. Several investigational agents are currently in phase 2 or 3 trials for VRE infection. Tigecycline demonstrates potent in vitro activity against enterococci $\left(\mathrm{MIC}_{90} 0.12 \mathrm{mg} / \mathrm{L}\right)$, regardless of vancomycin susceptibility [72].

\section{FUTURE STUDIES}

An urgent need exists for more agents to combat multi-drug-resistant, gram-positive pathogens such as MRSA. The glycopeptide oritavancin (LY333328) is in phase 3 clinical trials [73], whereas tigecycline has just been approved by the FDA. These agents, which require parenteral administration, exhibit substantial in vitro activity against a variety of gram-positive aerobes and anaerobes, including the multi-drug-resistant organisms described above. If controlled clinical trial data verify these agents' efficacy and tolerability, both drugs should become welcome additions to the armamentarium for the treatment of resistant, gram-positive pathogens.

New injectable cephalosporins with potent activity against MRSA and gram-negative bacteria, are also being investigated actively [74]. The new synthetic cephalosporin LB11058 has good affinity for staphylococcal penicillinbinding protein 2a (PBP2a). At appropriate doses, LB11058 was effective both in vitro and in vivo in a rat aortic MRSA endocarditis model [75]. This finding supports the development of this agent for the treatment of MRSA infections.

Telavancin (TD-6424) is a novel lipoglycopeptide that produces rapid, concentrationdependent killing of clinically relevant grampositive organisms in vitro, including MRSA and VRE. In vitro studies against specific MRSA isolates documented that telavancin was 4- to 30 -fold more potent than vancomycin and linezolid [76]. The findings of these studies collectively suggest that once-daily dosing of telavancin may provide an effective approach for the treatment of clinically relevant infections with resistant gram-positive organisms.
The development of parenteral carbapenems with activity against MRSA is ongoing [77]. The novel parenteral carbapenem ME1036 displays broad activity against aerobic gram-positive and gram-negative bacteria. Unlike other marketed beta-lactam antibiotics, ME1036 has excellent activity against multiple-drug-resistant, gram-positive bacteria such as MRSA. High affinity for PBP2a accounts for the activity of ME1036 against MRSA, for which the MIC $_{50}$ was approximately 300-fold lower than that of imipenem-cilastatin [78]. Thus, new carbapenems may be promising candidates to treat nosocomial bacterial infections caused by gram-positive and gram-negative bacteria, especially multi-drug-resistant gram-positive cocci.

Biofilm-associated infections are common, including ventilator-associated pneumonia and CR-BSI, and specific antibiotics targeted against such device-related infections are being developed. A recent study documented that ranbezolid inhibited biofilm formation to a greater extent than vancomycin, quinupristin-dalfopristin, and linezolid, and therefore may prove useful in the prevention and treatment of device-related infections caused by staphylococci [79]. It is only through the continued development of novel antimicrobial agents that new treatment strategies will emerge for multi-drug-resistant, gram-positive infections.

\section{REFERENCES}

1. Chambers HF. The changing epidemiology of Staphylococcus aureus? Emerg Infect Dis 2001;7:178-188.

2. Jones RN, Low DE, Pfaller MA. Epidemiologic trends in nosocomial and community-acquired infections due to antibiotic-resistant gram-positive bacteria: The role of streptogramins and other newer compounds. Diagn Microbiol Infect Dis 1999;33:101-112.

3. Cosgrove SE, Sakoulas G, Perencevich EN, et al. Comparison of mortality associated with methicillin-resistant and methicillin-susceptible Staphylococcus aureus bacteremia: A meta-analysis. Clin Infect Dis 2003;36: 53-59.

4. Taylor MD, Napolitano LM. Methicillin-resistant Staphylococcus aureus infections in vascular surgery: Increasing prevalence. Surg Infect 2004;5:180-187.

5. Zinn CS, Westh H, Rosdahl VT; Sarisa Study Group. An international multicenter study of antimicrobial resistance and typing of hospital Staphylococcus aureus 
isolates from 21 laboratories in 19 countries or states. Microb Drug Resist 2004;10:160-168.

6. National Nosocomial Infections Surveillance (NNIS) System Report, data summary, from January 1992 through June 2004, issued October 2004. Am J Infect Control 2004;32:470-485.

7. Francois P, Pittet D, Bento M, et al. Rapid detection of methicillin-resistant Staphylococcus aureus directly from sterile or nonsterile clinical samples by a new molecular assay. J Clin Microbiol 2003;4:254-260.

8. Huletsky A, Giroux R, Rossbach V, et al. New realtime PCR assay for rapid detection of methicillin-resistant Staphylococcus aureus directly from specimens containing a mixture of staphylococci. J Clin Microbiol 2004;42:1875-1884.

9. Warren DK, Liao RS, Merz LR, et al. Detection of methicillin-resistant Staphylococcus aureus directly from nasal swab specimens by a real-time PCR assay. J Clin Microbiol 2004;42:5578-5581.

10. Nagasawa Z, Manome I, Nagayama A. A rapid antimicrobial susceptibility test based on chemiluminescence assay and its application to screening of genotypes in vancomycin-resistant enterococci. I Infect Chemother 2004;10:220-226.

11. Clark NC, Weigel LM, Patel JB, et al. Comparison of Tn1546-like elements in vancomycin-resistant Staphylococcus aureus isolates from Michigan and Pennsylvania. Antimicrob Agents Chemother 2005;49:470-472.

12. Smith TL, Pearson ML, Wilcox KR, et al. Emergence of vancomycin resistance in Staphylococcus aureus. Glycopeptide-Intermediate Staphylococcus aureus Working Group. N Engl J Med 1999;340:493-501.

13. Bozdogan B, Ednie L, Credito K, et al. Derivatives of a vancomycin-resistant Staphylococcus aureus strain isolated at Hershey Medical Center. Antimicrob Agents Chemother 2004;48:4762-4765.

14. Hussain FM, Boyle-Vavra S, Shete PB, et al. Evidence for a continuum of decreased vancomycin susceptibility in unselected Staphylococcus aureus clinical isolates. J Infect Dis 2002;186:661-667.

15. Rybak MJ, Cha R, Cheung CM, et al. Clinical isolates of Staphylococcus aureus from 1987 and 1989 demonstrating heterogeneous resistance to vancomycin and teicoplanin. Diagn Microbiol Infect Dis 2005;51:119-125.

16. Fridkin SK, Hageman J, McDougal LK, et al, Vancomycin-Intermediate Staphylococcus aureus Epidemiology Study Group. Epidemiological and microbiological characterization of infections caused by Staphylococcus aureus with reduced susceptibility to vancomycin, United States, 1997-2001. Clin Infect Dis 2003;36:429-439.

17. Naimi TS, LeDell KH, Como-Sabetti K, et al. Comparison of community- and health care-associated methicillin-resistant Staphylococcus aureus infection. JAMA 2003;290:2976-2984.

18. Holden MT, Feil EJ, Lindsay JA, Peacock SJ, et al. Complete genomes of two clinical Staphylococcus aureus strains: Evidence for the rapid evolution of virulence and drug resistance. Proc Natl Acad Sci U S A 2004;10:9786-9791.
19. Kazakova SV, Hageman JC, Matava M, et al. A clone of methicillin-resistant Staphylococcus aureus among professional football players. N Engl J Med 2005;352: 468-475.

20. Carleton HA, Diep BA, Charlebois ED, Sensabaugh GF, Perdreau-Remington F. Community-adapted methicillin-resistant Staphylococcus aureus (MRSA): population dynamics of an expanding community reservoir of MRSA. J Infect Dis. 2004;190:1730-1738. Epub 2004 Oct 18.

21. Johnsson D, Molling P, Stralin K, Soderquist B. Detection of Panton-Valentine leukocidin gene in Staphylococcus aureus by LightCycler PCR: clinical and epidemiological aspects. Clin Microbiol Infect. 2004;10: 884-889.

22. Lewis JS 2nd, Jorgensen JH. Inducible clindamycin resistance in Staphylococci: Should clinicians and microbiologists be concerned? Clin Infect Dis 2005;40: 280-285.

23. Siberry GK, Tekle T, Carroll K, et al. Failure of clindamycin treatment of methicillin-resistant Staphylococcus aureus expressing inducible clindamycin resistance in vitro. Clin Infect Dis 2003;37:1257-1260.

24. Kollef MH, Sherman G, Ward S, et al. Inadequate antimicrobial treatment of infections: A risk factor for hospital mortality among critically ill patients. Chest 1999;115:462-474.

25. Garnacho-Montero J, Garcia-Garmendia JL, BarreroAlmodovar A, et al. Impact of adequate empirical antibiotic therapy on the outcome of patients admitted to the intensive care unit with sepsis. Crit Care Med 2003;31:2742-2751.

26. Li JZ, Willke RJ, Rittenhouse BE, Rybak MJ. Effect of linezolid versus vancomycin on length of hospital stay in patients with complicated skin and soft-tissue infections caused by known or suspected methicillinresistant staphylococci: Results from a randomized clinical trial. Surg Infect 2003;4:57-70.

27. Carpenter CF, Chambers HF. Daptomycin: Another novel agent for treating infections due to drug-resistant gram-positive pathogens. Clin Infect Dis 2004; 38:994-1000.

28. Anstead GM, Owens AD. Recent advances in the treatment of infections due to resistant Staphylococcus aureus. Curr Opin Infect Dis 2004;17:549-555.

29. Fritsche TR, Jones RN. Antimicrobial activity of tigecycline (GAR-936) tested against 3498 recent isolates of Staphylococcus aureus recovered from nosocomial and community-acquired infections. Int J Antimicrob Agents 2004;24:567-571.

30. Fritsche TR, Kirby JT, Jones RN. In vitro activity of tigecycline (GAR-936) tested against 11,859 recent clinical isolates associated with community-acquired respiratory tract and gram-positive cutaneous infections. Diagn Microbiol Infect Dis 2004;49:201-209.

31. Muralidharan G, Micalizzi M, Speth J, et al. Pharmacokinetics of tigecycline after single and multiple doses in healthy subjects. Antimicrob Agents Chemother 2005;49:220-229. 
32. Napolitano LM. Hospital-acquired and ventilator-associated pneumonia: What's new in diagnosis and treatment? Am J Surg 2003;186: 4S-14S.

33. Rello J, Torres A, Ricart M, et al. Ventilator-associated pneumonia by Staphylococcus aureus: Comparison of methicillin-resistant and methicillin-sensitive episodes. Am J Respir Crit Care Med 1994;150:1545-1549.

34. Fagon J, Patrick H, Haas DW, et al. for the Nosocomial Pneumonia Group. Treatment of gram-positive nosocomial pneumonia: Prospective randomized comparison of quinupristin/dalfopristin versus vancomycin. Am J Respir Crit Care Med 2000;161:753-762.

35. Rubinstein E, Cammarata SK, Oliphant $\mathrm{TH}$, et al. Linezolid versus vancomycin in the treatment of hospitalized patients with nosocomial pneumonia: A randomized, double-blind, multicenter study. $\underline{\text { Clin Infect }}$ Dis 2001;32:402-412.

36. Wunderink RG, Rello J, Cammarata SK, et al. Linezolid vs. vancomycin: Analysis of two double-blind studies of patients with methicillin-resistant Staphylococcus aureus nosocomial pneumonia. Chest 2003;124: 1789-1797.

37. Kollef MH, Rello J, Cammarata SK, et al. Clinical cure and survival in gram-positive ventilator-associated pneumonia: Retrospective analysis of two doubleblind studies comparing linezolid with vancomycin. Intensive Care Med 2004;30:388-394.

38. Conte JE Jr, Golden JA, Kipps J, et al. Intrapulmonary pharmacokinetics of linezolid. Antimicrob Agents Chemother 2002;46:1475-1480.

39. Honeybourne D, Tobin C, Jevons G, et al. Intrapulmonary penetration of linezolid. I Antimicrob Chemother 2003;51:1431-1434.

40. Lamer C, de Beco V, Soler P, et al. Analysis of vancomycin entry into pulmonary lining fluid by bronchoalveolar lavage in critically ill patients. Antimicrob Agents Chemother 1993;37:281-286.

41. Georges H, Leroy O, Alfandari S, et al. Pulmonary disposition of vancomycin in critically ill patients. Eur J Clin Microbiol Infect Dis 1997;16:385-388.

42. Nasraway SA, Shorr AF, Kuter DJ, et al. Linezolid does not increase the risk of thrombocytopenia in patients with nosocomial pneumonia: Comparative analysis of linezolid and vancomycin use. $\underline{\text { Clin Infect }}$ Dis 2003;37:1609-1616.

42a. Silverman JA, Mortin LI, Vanpraagh AD, et al. Inhibition of daptomycin by pulmonary surfactant: in vitro modeling and clinical impact. I Infect Dis 2005; 191:2149-2152.

43. Wilson MA. Skin and soft-tissue infections: Impact of resistant gram-positive bacteria. Am J Surg 2003;186: 35S-41S; discussion 42S-43S, 61S-64S.

44. Eron LJ, Lipsky BA, Low DE, Nathwani D, Tice AD, Volturo GA; Expert panel on managing skin and soft tissue infections. Managing skin and soft tissue infections: expert panel recommendations on key decision points. J Antimicrob Chemother. 2003;52(Suppl 1):i3-17.

45. Nichols RL, Graham DR, Barriere SL, et al. Treatment of hospitalized patients with complicated gram-positive skin and skin structure infections: Two random- ized, multicentre studies of quinupristin/dalfopristin versus cefazolin, oxacillin or vancomycin. Synercid Skin and Skin Structure Infection Group. J Antimicrob Chemother 1999;44:263-273.

46. Stevens DL, Herr D, Lampiris $H$, et al. Linezolid versus vancomycin for the treatment of methicillin-resistant Staphylococcus aureus infections. Clin Infect Dis 2002;34:1481-1490.

47. Weigelt J, Itani KM, Lau WK, et al. Linezolid vs. vancomycin for complicated skin and skin structure infections presumed or known to be caused by methicillin-resistant $S$. aureus. San Diego, California. Infectious Disease Society of America Annual Meeting 2003: Poster \#314.

48. Weigelt J, Kaafarani HM, Itani KM, et al. Linezolid eradicates MRSA better than vancomycin from surgical-site infections. Am J Surg 2004;188:760-766.

49. Stein GE, Schooley SL, Peloquin CA, et al. Pharmacokinetics and pharmacodynamics of linezolid in obese patients with cellulitis. Ann Pharmacother 2005 Feb 8; [Epub ahead of print].

50. Anonymous. Daptomycin (Cubicin) for skin and softtissue infections. Med Lett Drugs Ther 2004;46:11-12.

51. Steenbergen JN, Alder J, Thorne GM, et al. Daptomycin: A lipopeptide antibiotic for the treatment of serious gram-positive infections. J Antimicrob Chemother 2005 Feb 10; [Epub ahead of print].

52. Arbeit RD, Maki D, Tally FP, Campanaro E, Eisenstein BI; Daptomycin 98-01 and 99-01 Investigators. The safety and efficacy of daptomycin for the treatment of complicated skin and skin-structure infections. Clin Infect Dis. 2004;38:1673-81. Epub 2004 May 20

53. Raghavan M, Linden PK. Newer treatment options for skin and soft-tissue infections. Drugs 2004;64: 1621-1642.

54. Seltzer E, Dorr MB, Goldstein BP, et al. Once-weekly dalbavancin versus standard-of-care antimicrobial regimens for treatment of skin and soft-tissue infections. Clin Infect Dis 2003;37:1298-1303.

55. Lin G, Credito K, Ednie LM, et al. Antistaphylococcal activity of dalbavancin, an experimental glycopeptide. Antimicrob Agents Chemother 2005;49:770-772.

56. Loutit JS, Huang SM, Porter SB. Efficacy and safety of oritavancin in the treatment of diabetic patients with complicated skin and skin structure infections. Int J Infect Dis 2004;8(Suppl 1):S18 (Abstract).

57. Ellis-Grosse EJ, Loh E. Tigecycline is safe and effective in the treatment of skin and skin structure infections: results of two double-blind phase 3 comparison studies with vancomycin/aztreonam (abstract FP-C6). Presented at the $9^{\text {th }}$ Western Pacific Congress on Chemotherapy and Infectious Diseases, December 1-5, 2004, Bangkok, Thailand.

58. Lipsky BA, Itani K, Norden C, and the Linezolid Diabetic Foot Infections Study Group. Treating foot infections in diabetic patients: A randomized, multicenter, open-label trial of linezolid vs. ampicillinsulbactam/amoxicillin-clavulanate. Clin Infect Dis 2004;38:17-24. 
59. Lipsky BA, Stoutenburgh U. Daptomycin for treating infected diabetic foot ulcers: Evidence from a randomized, controlled trial comparing daptomycin with vancomycin or semi-synthetic penicillins for complicated skin and skin-structure infections. I Antimicrob Chemother 2005;55:240-245.

60. Edmond MB, Wallace SE, McClish DK, et al. Nosocomial bloodstream infections in United States hospitals: A three-year analysis. Clin Infect Dis 1999;29: 234-244.

61. Cosgrove SE, Sakoulas G, Perencevich EN, et al. Comparison of mortality associated with methicillin-resistant and methicillin-susceptible Staphylococcus aureus bacteremia: A meta-analysis. Clin Infect Dis 2003;36: 53-59.

62. Whitby M, McLaws ML, Berry G. Risk of death from methicillin-resistant Staphylococcus aureus bacteraemia: a meta-analysis. Med J Aust 2001;175:264-267.

63. Lodise TP, McKinnon PS, Swiderski L, et al. Outcomes analysis of delayed antibiotic treatment for hospital-acquired Staphylococcus aureus bacteremia. Clin Infect Dis 2003;36:1418-1423.

64. Fridkin SK, Hageman J, McDougal LK, et al. Epidemiological and microbiological characterization of infections caused by Staphylococcus aureus with reduced susceptibility to vancomycin, United States, 1997-2001. Clin Infect Dis 2003;36:429-439.

65. Charles PG, Ward PB, Johnson PDR, et al. Clinical features associated with bacteremia due to heterogeneous vancomycin-intermediate Staphylococcus aureus. Clin Infect Dis 2004;38:448-451.

66. Sakoulas G, Moise-Broder PA, Schentag J, et al. Relationship of MIC and bactericidal activity to efficacy of vancomycin for treatment of methicillin-resistant Staphylococcus aureus bacteremia. J Clin Microbiol 2004;42:2398-2402.

67. Raad I, Darouiche R, Vazquez J, et al. Efficacy and safety of weekly dalbavancin therapy for catheter-related bloodstream infection caused by gram-positive pathogens. Clin Infect Dis 2005;40:374-380.

68. Linden PK. Treatment options for vancomycin-resistant enterococcal infections. Drugs. 2002;62:425-441.

69. Moellering RC, Linden PK, Reinhardt J, et al. The efficacy and safety of quinupristin/dalfopristin for the treatment of infections caused by vancomycinresistant Enterococcus faecium. Synercid EmergencyUse Study Group. I Antimicrob Chemother 1999;44: 251-261.

70. El-Khoury J, Fishman JA. Linezolid in the treatment of vancomycin-resistant Enterococcus faecium in solid organ transplant recipients: Report of a multicenter compassionate-use trial. Transpl Infect Dis 2003;5:121-125.
71. Raad I, Hachem R, Hanna H, et al. Prospective, randomized study comparing quinupristin-dalfopristin with linezolid in the treatment of vancomycinresistant Enterococcus faecium infections. J Antimicrob Chemother 2004;53:646-649.

72. Cercenado E, Cercenado S, Gomez JA, Bouza E. In vitro activity of tigecycline (GAR-936), a novel glycylcycline, against vancomycin-resistant enterococci and staphylococci with diminished susceptibility to glycopeptides. I Antimicrob Chemother 2003;52: 138-139.

73. Guay DR. Oritavancin and tigecycline: Investigational antimicrobials for multi-drug-resistant bacteria. Pharmacotherapy 2004;24:58-68.

74. Tsuji M, Takema M, Miwa $\mathrm{H}$, et al. In vivo antibacterial activity of S-3578, a new broad-spectrum cephalosporin: Methicillin-resistant Staphylococcus aureus and Pseudomonas aeruginosa experimental infection models. Antimicrob Agents Chemother 2003;47: 2507-2512.

75. Vouillamoz J, Entenza JM, Hohl P, et al. LB11058, a new cephalosporin with high penicillin-binding protein $2 \mathrm{a}$ affinity and activity in experimental endocarditis due to homogeneously methicillin-resistant Staphylococcus aureus. Antimicrob Agents Chemother 2004;48:4322-4327.

76. Hegde SS, Reyes N, Wiens T, et al. Pharmacodynamics of telavancin (TD-6424), a novel bactericidal agent, against gram-positive bacteria. Antimicrob Agents Chemother 2004;48:3043-3050.

77. Ueda Y, Sunagawa M. In vitro and in vivo activities of novel 2-(thiazol-2-ylthio)-1-beta-methylcarbapenems with potent activities against multi-resistant gram-positive bacteria. Antimicrob Agents Chemother 2003;47:2471-2480.

78. Kurazono M, Ida T, Yamada K, et al. In vitro activities of ME1036 (CP5609), a novel parenteral carbapenem, against methicillin-resistant staphylococci. Antimicrob Agents Chemother 2004;48:2831-2837.

79. Mathur T, Bhateja P, Pandya M, et al. In vitro activity of RBx 7644 (ranbezolid) on biofilm producing bacteria. Int J Antimicrob Agents 2004;24:369-373.

Address reprint requests to: Lena M. Napolitano MD, FACS, FCCM, FCCP University of Michigan School of Medicine 1500 East Medical Center Drive Ann Arbor, MI 48190-0033

E-mail: lenan@umich.edu 